\title{
The influence of fine particles composition on optimal design of sand control in offshore oilfield
}

\author{
Fucheng Deng $\cdot$ Jingen Deng $\cdot$ Wei Yan $\cdot$ \\ Haiyan Zhu $\cdot$ Lan Huang $\cdot$ Zijian Chen
}

Received: 6 September 2012/ Accepted: 2 December 2012/Published online: 20 April 2013

(C) The Author(s) 2013. This article is published with open access at Springerlink.com

\begin{abstract}
The fine particles have significant influence for sand control mode selection. According to investigation and analysis, we learn that the gravel packing has been used widespread in sand control when the contents of fine particles are high. Based on designing the pre-packed screen, different fine particles sand control research is completed combining with test method. (1) We find that the sequence of fine particles flowing into the well has an enormous impact on the screen jam rate, and the smaller the fine particle diameter, the more obvious the screen plugging. The jam rate for the pure clay is five times with pure finesilty sand, and four times with mixture of the fine-silty sand and the clay. When the experimental achieve octet stability, the Fluid Productivity Index Per-Meter (FPIPM) of the pure clay is pretty much equivalent with the mixture of the finesilty sand and the clay. It is $70 \%$ of the pure fine-silty sand FPIPM but has limited influence to effectiveness of the blockage. (2) Sand control selection in the offshore oilfield suggests the gravel packing will be applied when the fine particles content is over $5 \%$. Compared to this select range, it is conservative and experiments show that the fine particles content achieves $100 \%$, the pre-packed screen also can cope with sand control effectively. When comparing with experimental result about the gravel packing sand control under the same condition, the both FPIPM in steady is same. So, it is more suitable to be widely used combined with the production cost.
\end{abstract}

Keywords Pre-packed screen · Gravel packing · Fine particles · Sand control design · FPIPM

F. Deng $(\bowtie) \cdot$ J. Deng $\cdot$ W. Yan $\cdot$ H. Zhu $\cdot$ L. Huang $\cdot$ Z. Chen State Key Laboratory of Petroleum Resource and Prospecting, China University of Petroleum, Beijing 102249, China e-mail: dengfucheng128@163.com

\section{Introduction}

There is a lot of research on the blueprint of sand control (Bennett et al. 1998; Farrow et al. 2004; McCarthy and Mickelburgh 2010; Schwartz 1969; Slayter et al. 2008). But the gravel packing is used in concert with other screen in oil field which is fit for the formation of high fine particles content. Such as, Tiffin (Tiffin et al. 1998, 2003) introduced two new parameters in sand control with the sand particle size distribution: sorting characteristics $(\mathrm{SC}=\mathrm{d} 10 / \mathrm{d} 95)$ and fine particles (the quality percentage of $<45 \mu \mathrm{m}$ particles), and the gravel packing completion was used in the formation of high fine particles content. Mohamad et al. (2008) published an article in the JPT which showed fine particles $(<45 \mu \mathrm{m})$ content with $35 \%$. The gravel packing was used in the initial stage, and it found that the skin was very high under this way. Therefore, wire-wrapped screens were used in some part of wells, but the production differential pressure should be accurately restricted. Field $\mathrm{A}$ and $\mathrm{B}$, which the grain distribution are $\mathrm{SC}<10$ and $\mathrm{UC}<3$, and the fine particles contents are greater than $5 \%$. For the formation is weak cementation, field A applied high quality screen independent in producing for many years. But the sand production is very high.

Because of the complication and risk in the deep water environment, gravel pack completion is used in the development of most of the deep water oil and gas fields. And the water injection well use the casing perforation, wire wrapped screen and high quality screen. Based on Tiffin method and Bennett method (Leo et al. 2002; Markestad and Christie 1996), Schlumberger company summarizes well open hole completion sand control design method of the offshore horizontal according to the implementation experiences of four field completion engineers, 
as described below: (1) no matter deep or shallow water, when the well design lifetime is longer than the time of pore pressure failure in rocks that causes rock particles stress to increase, the gravel packing completion can be used in sand control. (2) When the water depth is over $1500 \mathrm{ft}(457 \mathrm{~m})$, gravel packing completion can be all applied to both injection wells and production wells. (3) When the water depth is less $1500 \mathrm{ft}, \mathrm{d} 50<75 \mu \mathrm{m}$ (very fine siltstone reservoir), both injection wells and production wells, no matter how heterogeneity of the reservoir conditions does, gravel packing completion can be accepted. (d50 $>75 \mu \mathrm{m}$ : UC $>5, \mathrm{SC}>10$ and fine siltstone $>5$.

The fine particles can be divided into fine-silty sand $(\mathrm{d} 50=38 \mu \mathrm{m})$ and clay $(\mathrm{d} 50=2 \mu \mathrm{m})$ (Ballard et al. 2008; Byrne and Waggoner 2009; Byrne et al. 2009, 2010). After investigation we found that there are only few studies of different fine particles composition on the effect of the sand control. Through the analysis of various oilfield formation data, we realized that the fine particle is more or less exists in the formation. As we know, the cost of gravel packing is several times higher than independent high quality screen, if the well completion is prevalent in gravel packing, this will increase not only the operation time, but also the cost of well completion. As we all know, the prepacked screen is also one of many options of sand control methods. Based on the pre-packed screen design and numerous laboratory experiments, this paper is emphasis on the effects of the fine particle to jam the pre-packed screen.

\section{Introduction to gravel pre-packed screen}

There are three parts in pre-packed screen: the outer protective layer, the packing filtering layer and the base pipe.
Since the wire wrap screen (WWS), mesh screen (MS) and slotted screen are less sensitive to shale content, especially the WWS and slotted screen, they are suitable to cooperate with the pre-packed gravel. Moreover, due to the low cost of slotted screen and WWS, this paper was working on a laddershaped opening model to fit the outer protective layer, with $a=0.3 \mathrm{~mm}$ accuracy, and every wire is welded to form an entity by metal bars. As for the base pipe, we prefer network, and the base pipe is distributed with flowing holes. In order to prevent the gravel pre-packed falling from the screen under certain pressure, the mesh monolayer with $0.3 \mathrm{~mm}$ gap width is outside of the base pipe. Considered the influence of the screen weight operate to the process, we chose the stainless steel which is more flexible in elasticity and lighter in weight as the wire wrapped protective layer outside the screen and the inner base pipe. And there are flowing holes on the steel in order to make the formation fluid flow more smoothly. In this paper, the packing thickness of the pre-packed screen is $20 \mathrm{~mm}$, the size of the gravel is $20-40 \mathrm{mesh}$, and the length of the screen is $35 \mathrm{~cm}$. The schematic diagram (left) and the physical map (right) are shown in Fig. 1.

\section{Introduction to the experiment}

The former researches of sand control screen performance are all based on some single units of sand control, for small size of this kind of simulating experiments there is a huge different between lab conditions and real production. In this case, the author did a series of comparative evaluation experiments using the simulative experiment device of oil well sand control (Wang et al. 2011; Zou et al. 2009) in China University of Petroleum (Beijing). This set of experiment device can do the evaluating experiment of wellbore oil and sand radius flow regulations under
Fig. 1 Sketch of gravel prepacking screen
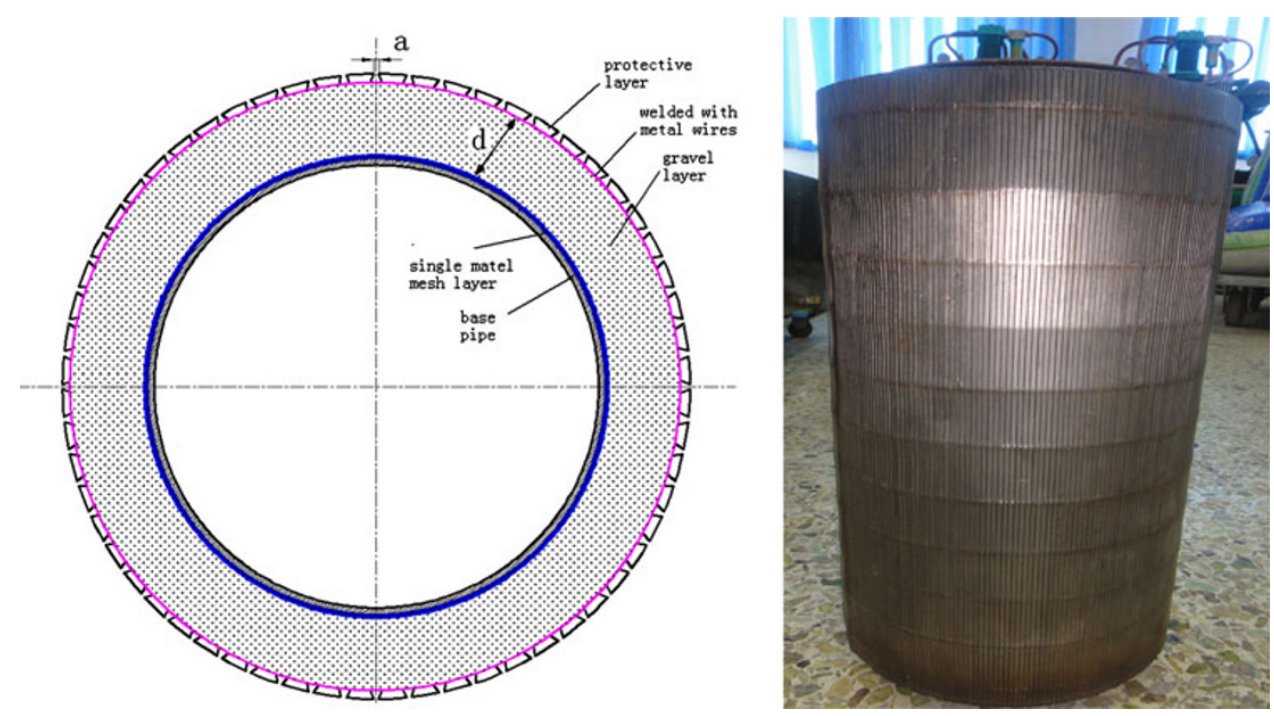
Fig. 2 Set-up diagram of oil well sand control screen evaluation experiment. 1 containers; 2 high-pressure pump; 3,8 pressure sensor; 4 flowmeter; 5 safety valve, 6 autoclave; 7 deceleration check valve; 9 oil and sand separator; 10 oil sands cleaner; 11 data acquisition card

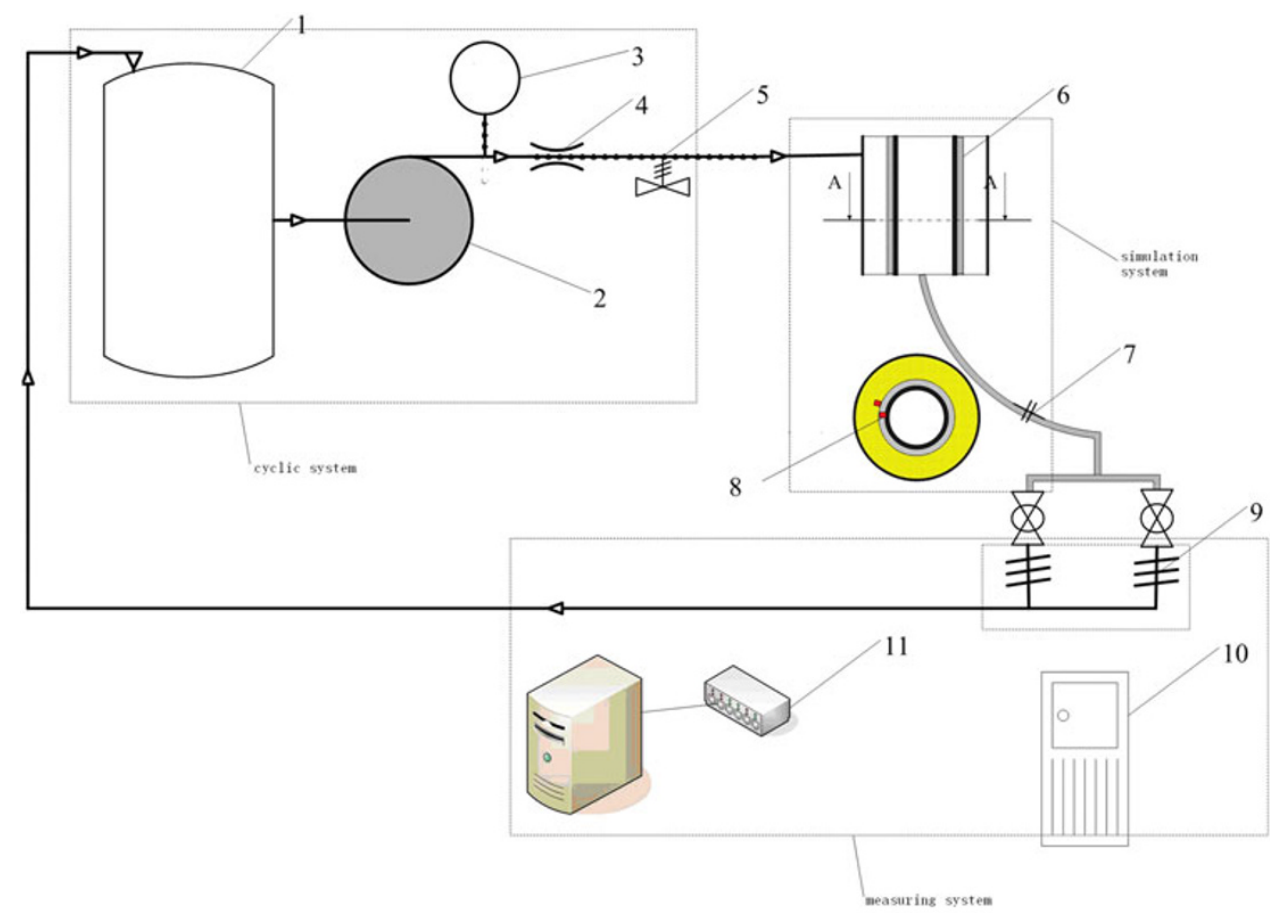

confining pressure and can do better evaluation of screen performance from the integral view, because it's undertaking with a full-size sand control pipe and simulates stable reservoir producing conditions using diaphragm pump, safety valve and a series of devices. During the experiment, we can analyze how oil production rate and sand production rate change with time by measuring the flow rate, pressure and sand production rate and other parameters.

\section{Device for experiment}

This set of device including five parts: oil and sand mixing system, pressure and liquid supply circulation system, sand producing simulation device, oil and sand simulation system, data auto-acquisition system (Fig. 2).

\section{Sand control experiment process}

(1) After setting and debugging the equipment, we inject some white oil. Make sure the oil is flowing from all the entrance holes and check the pressure testing system. (2) Trice up the pre-packed screen and put it in the pressure vessel, lay a rubber cushion as seal ring on the top of the vessel, then padlock the pressure vessel cap. (3) Mix different sands according to experiment demand, and add clay to the sand in a certain ratio, then pour the white oil, mixed sand and clay into the oil-sand blending tank in a certain ratio. (4) Rig up circulation system pipeline, pressure sensor of the import and export, filter of sand produced, data acquisition card, and set pump pressure according to the formation pressure. (5) Turn on computer data detection and acquisition system to record the pressure and flow rate of every point in real-time during the experiment. (6) Separate the sand from oil using the shaker, clean the sand produced using kerosene and weigh the sand, then analyze the sand using laser grain-size analysis. (7) Repeat the above procedures until the end of the experiment. Finally clean the device.

\section{Optimization principles}

In order to evaluate the performance of the pre-packed screen in the simulative production process, and also in oilfield production practice, finding a sand control method which is suitable for long-term development in offshore oilfield and balance the contradiction between sand control and production, propose the principle that we should improve productivity as much as possible under the guarantee of sand control efficiency, so we need to compare the change rules of sand production and productivity under different sand control methods, then we can optimize the packing way of pre-packed screen based on the above principle. The sand production we use here is the sand collected in each experiment, and combined with oil volume produced we can calculate the sand concentration. Production is measured by the metric fluid productivity index (Wan 2000), shown in formula (1).

$J=\frac{Q}{\left(p_{\mathrm{e}}-p_{\mathrm{wf}}\right) h}$

where: J-fluid productivity index per meter (FPIPM), $\mathrm{m}^{3} /(\mathrm{m} \times \mathrm{d} \times \mathrm{MPa}) ; \mathrm{q}$-flow rate, $\mathrm{m}^{3} / \mathrm{d} ; \mathrm{h}$-effective 
Fig. 3 Initial data of production rate and pressure with pure clay

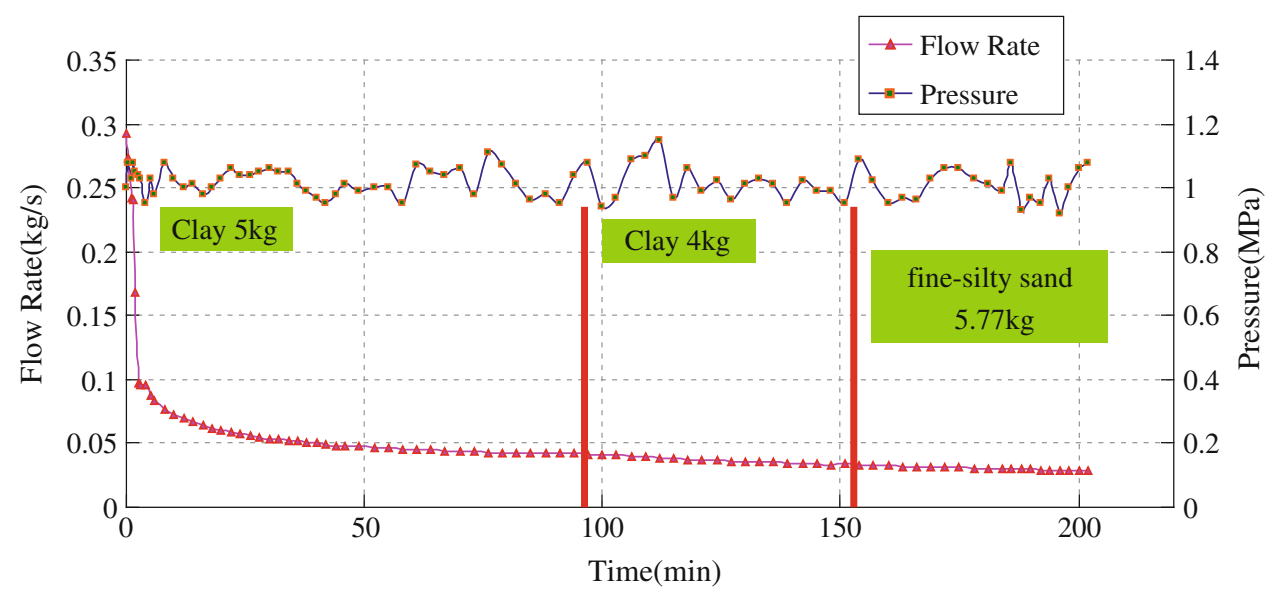

overflow length of the screen, $\mathrm{m}$; Pe-reservoir pressure, $\mathrm{MPa}$; Pwf—bottom hole gas flowing pressure, MPa.

\section{Comparative experiment research of different fine particles}

The influence of sand production sequence to screen about the experimental results and analysis

Since the clay can plug the pore of the screen and reduce production in the late period, clay content is crucial to the selection of sand control methods in the design process. Considering the shale content limit, when shale content is very high, we assumed that there is only clay existed during the production. Therefore, we performed the antiplugging of the screen under the conditions of the relative content of clay to liquid production ( $90 \%$ of smectite). In the test, $5 \mathrm{~kg}$ clay is mixed in test oil, at this time the clay content is $2 \%$ (the comparing of clay and the test oil). Through the observation of the oil color in the oil-out, the oil is yellow in the initial period for containing a certain amount of clay. In $20 \mathrm{~min}$, the oil gradually change to limpid. When the flow regime tend is stable, $4 \mathrm{~kg}$ clay is mixed into the blending tank, this time the clay concentration reaches $4 \%$. In the initial 3 min the oil color shown a yellowish, then turn to clear again. After the flow regime is in stable, $5.77 \mathrm{~kg}$ fine-silty sand (standard industrial 160-200 mesh) is mixed into the blending tank, the flow fall subsequently. Figure 3 shows initial data of production rate and pressure with pure clay.

As is shown in Fig. 4, we found that the mud cake separated some distinct layers. The inner layer of the mud cake which adjoins by the screen is fine and smooth with clay. The out layer of the mud cake is coarser than the inner layer, for its apparently fully fine-silty sand component. It shows that a layer of mud cake will be firstly attached on the screen during the experiment. Then the added clay and fine-silty sand adhere onto the previous layer and gradually accumulate more mud cake. The thickness of mud cake increases with the adding speed of clay and fine-silty sand, and the flow rate slow down gradually at the same time.

During the productive process of production well, the weakly consolidated sands produce tiniest particles of clay at first and then free sand. When the productive velocity reaches a particular level, the formation suddenly produces a huge amount of sand. The whole experimental simulation is the same as the real sand production in the process of production wells, and the sand control design focuses on preventing free sand into the productive pipelines that cause the productive pipeline to be erosive. According to the experimental results, the pre-packed screen can block these clay and free sand outside the screen, gradually they accumulate a layer of mud cake commendably. When making a selection of sang control, especially to those deep-water oilfields (depth over $1500 \mathrm{ft}$ ), the field staff always tend to select the gravel packing. However, this method is relatively conservative, which increase both the operational time and the cost of well completion. Therefore, expanding the optimal principles of sand controlling should be considered, especially about select range of fine-silty sand. Screens can be used for 5 years, and introducing the pre-packed screen to replace the gravel packing will be an effective improvement after considering the formation characteristic.

The experiment result of the pure fine-silty sand

The fine particles $(<45 \mu \mathrm{m})$ are very important on jamming the screen. In order to find the theory of plugging mechanism of the pre-packed screen, the fine-silty sand with standard industrial 160-200 mesh is applied in simulation experiment, and the sand content is $6 \%$. Figure 5 shows initial data of production rate and pressure with pure fine-silty sand. Obviously, from the figure that, in the initial production stage, the flow rates is very high, but they also decline rapidly with the blockage of the screen. Especially, ten minutes at the 

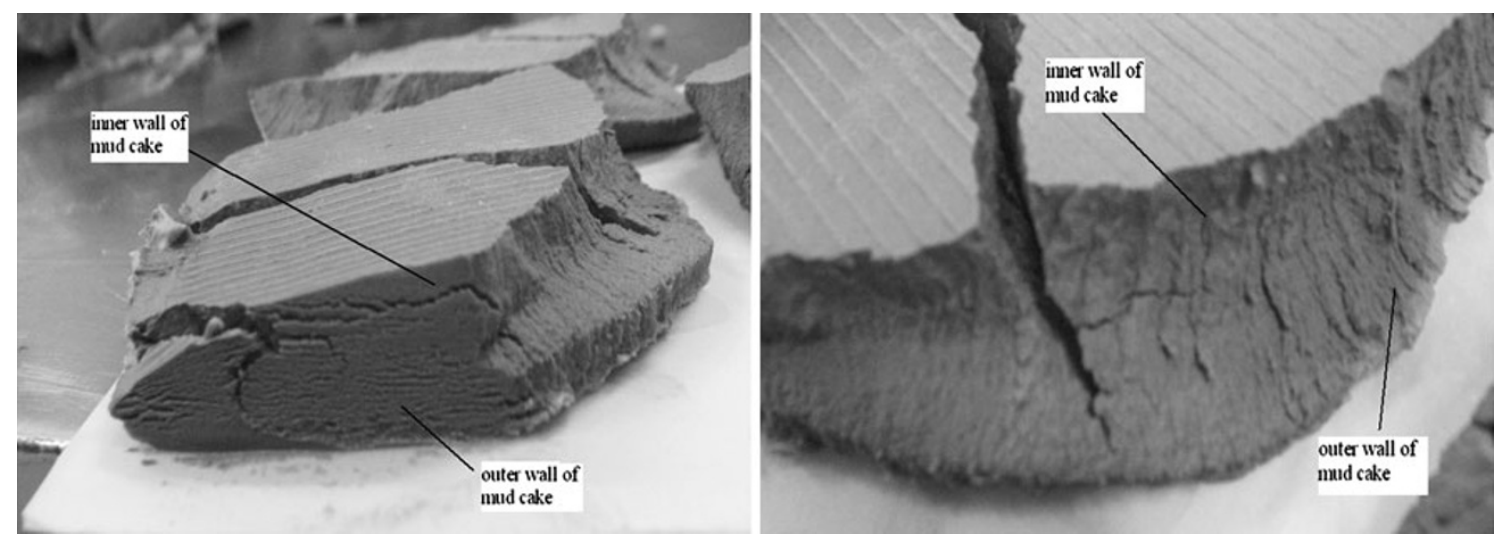

Fig. 4 Cross-section diagram of the mixture of the clay and fine-silty sand

Fig. 5 Initial data of production rate and pressure with pure fine-silty sand

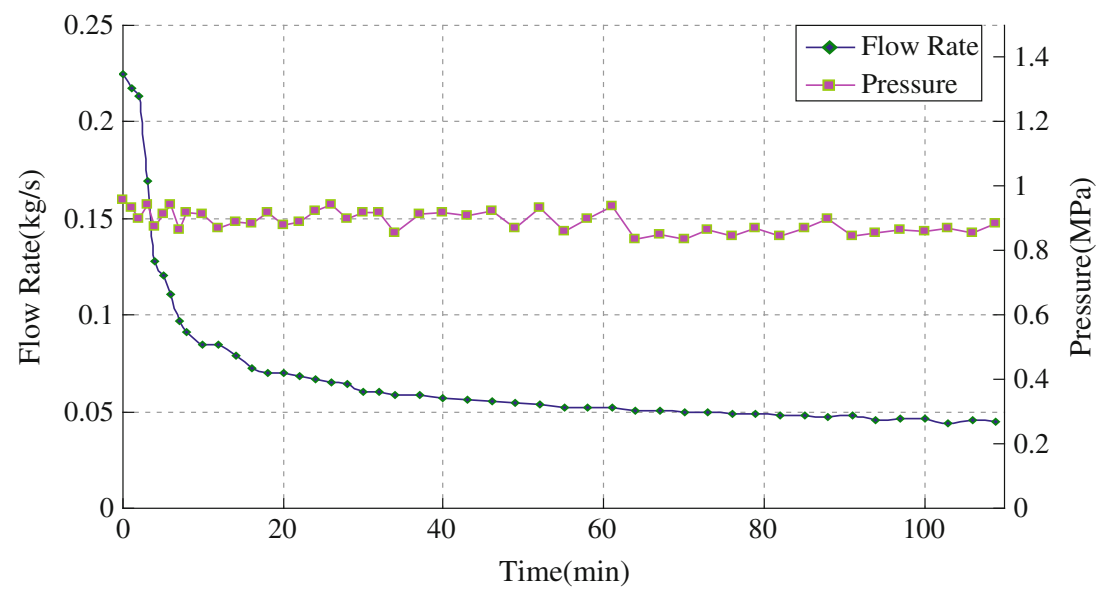

beginning of the experiment, the production flow down close to $70 \%$ with initial. It means that the fine-silty sand has dramatically effective clog for the screen in the producing time, also reduces the production by a wide margin.

In the test, there are $15 \mathrm{~kg}$ fine-silty sand content and $3 \%$ the oil sand ratio. In the first $5 \mathrm{~min}$ of the experiment, relatively turbid oil is flushing out. It tells us the production is high, and the sand content is also high. With the production gradually reduces, the oil become transparent, and the FPIPM reaches stability. As is shown in Fig. 6, the color of the mud cake is the original colors of the fine-silty sand for no clay mixed.

The experiment result of the mixture of the fine-silty sand and clay

In order to clarify the sand control effect of the clay content for the pre-packed screen, in the same experimental conditions, the tests of the mixture of the fine-silty sand and clay are mixed with the sand content of $6 \%$, and the clay content of $10 \%$. In the early of the test, it will be mixed into the oil.

Figure 7 tells us how the overflow rate and producing pressure drop changes with time using pre-packed screen of the mixture of the fine-silty sand and clay. From the graph, it is obviously show us that the flow rates of all the three are very high in the initial production stage, but they also decline very soon with the blockage of the screen, then the liquid production achieves initial stabilization along with production.

Comparative analysis with different fine particles

Obviously, from Fig. 8 that the FPIPM declines fast with content of the clay, and the higher the clay content is, the faster the screen is jammed. The jam rate for the pure clay is 5 times with pure fine-silty sand. The jam rate for the mixture of the fine-silty sand and clay is $25 \%$ higher than the pure fine-silty sand. According to this jamming result, during the whole process of sand production, the sequences of clay and fine-silty sand enter into screens has no difference from final jamming effect but the time in jamming process. Thus, in the productive process, it is necessary to control producing pressure, which can raise the effective previous permeability of screens as well as reduce the proportion of clay in oil, and increase prophase production.

Figure 9 shows us that the test in the stability on mixing the clay is significant influence with the FPIPM. The FPIPM 

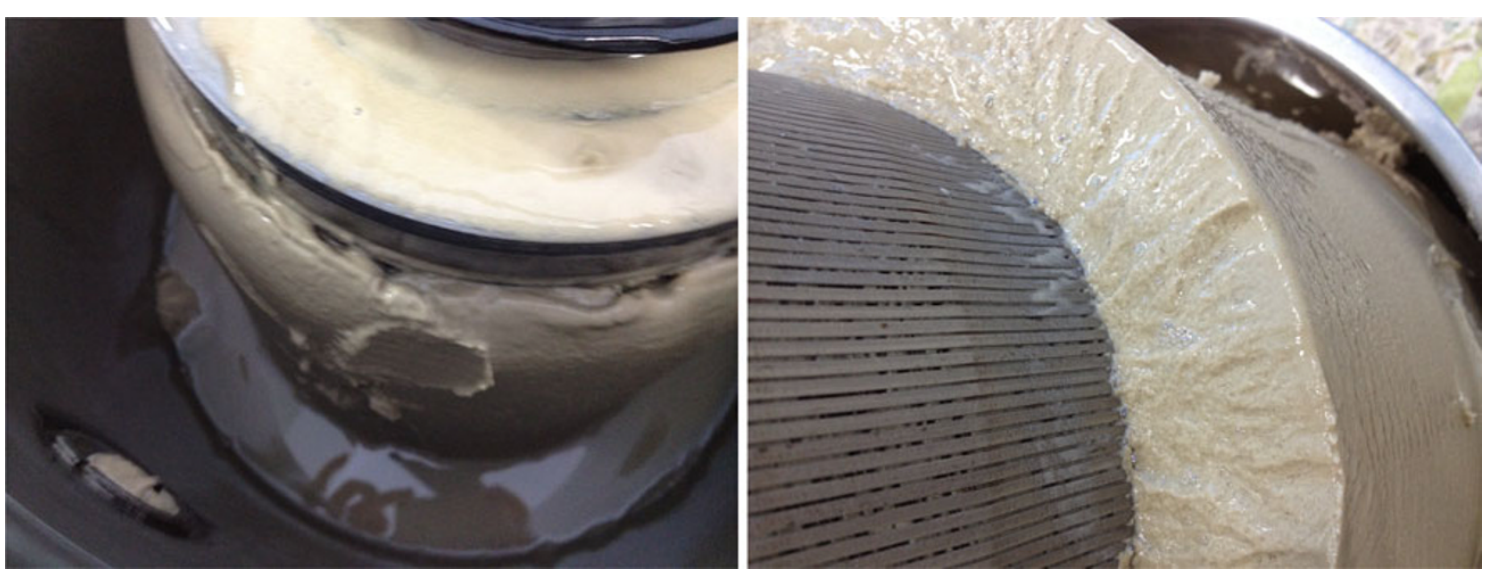

Fig. 6 Post-experiment mud cake of pure fine-silty sand

Fig. 7 Initial data of production rate and pressure with mixture of the fine-silty sand and clay

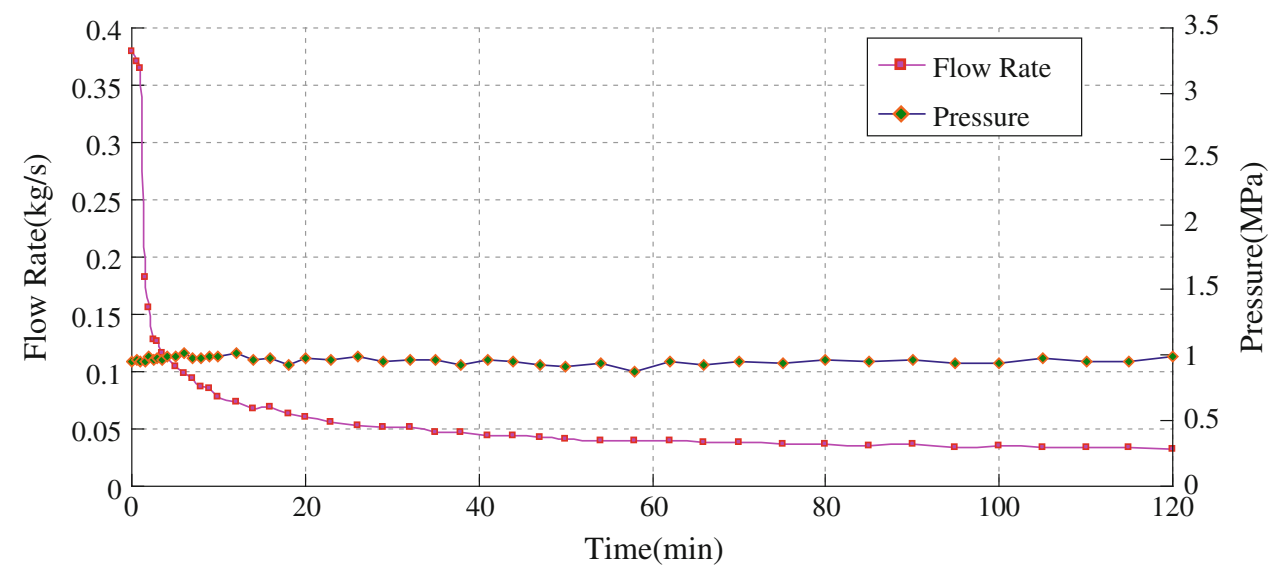

of the mixture of the fine-silty sand and clay declines $30 \%$ comparing to the pure fine-silty sand. The FPIPM in stable of the pure clay declines $35.7 \%$ relative to the pure finesilty sand. And the FPIPM in stable of mixture of the finesilty sand and clay is $9 \%$ higher than pure clay. For the same pre-packed screen, the smaller the grain size of the fine particles is, the better effect on the sand control is jammed. And the fine particles can reduce the production directly. This phenomenon is convinced that jamming capacity of clay is greater than fine-silty sand. The higher the content of clay is, the stronger plugging ability to screen is.

\section{Comparative analysis with gravel packing sand control}

To establish a high quality screen and $30 \mathrm{~mm}$ thickness with 20-40 mesh gravel packing layer sand control model, and it is also applied the same fine-silty sand and clay experiment simulating conditions. The specific data with the test is as follows:

It is noticeable from Fig. 10 that the FPIPM of the prepacked screen in the whole production stages is almost equivalent with the gravel packing sand control. It shows that two sand control methods have the same effect for fine particles. If the pre-packed screen is used in the sand control process, it has a great impact and save a large number of operation time and cost. In selecting process of sand control in offshore oilfield, Tiffin had suggested that the gravel packing could be applied to well completion when the content of fine particles is over $5 \%$. This range is relatively conservative. Through several experiments, prepacked screen can prevent sand control effectively when the content of fine particles reaches to $100 \%$. That means, to a certain extent, pre-packed screen can replace the gravel packing in most areas, and the new solution will save both operational time and production expenses.

\section{Conclusions}

1. The sand control comparative experiment in different fine particles of pre-packed screen was built to study. From these simulation analysis, we found that the fine particles $(<45 \mu \mathrm{m})$ have strongly blocking to the well 
Fig. 8 FPIPM comparative diagram of different fine particles

Fig. 9 FPIPM in stable comparative diagram of different fine particles
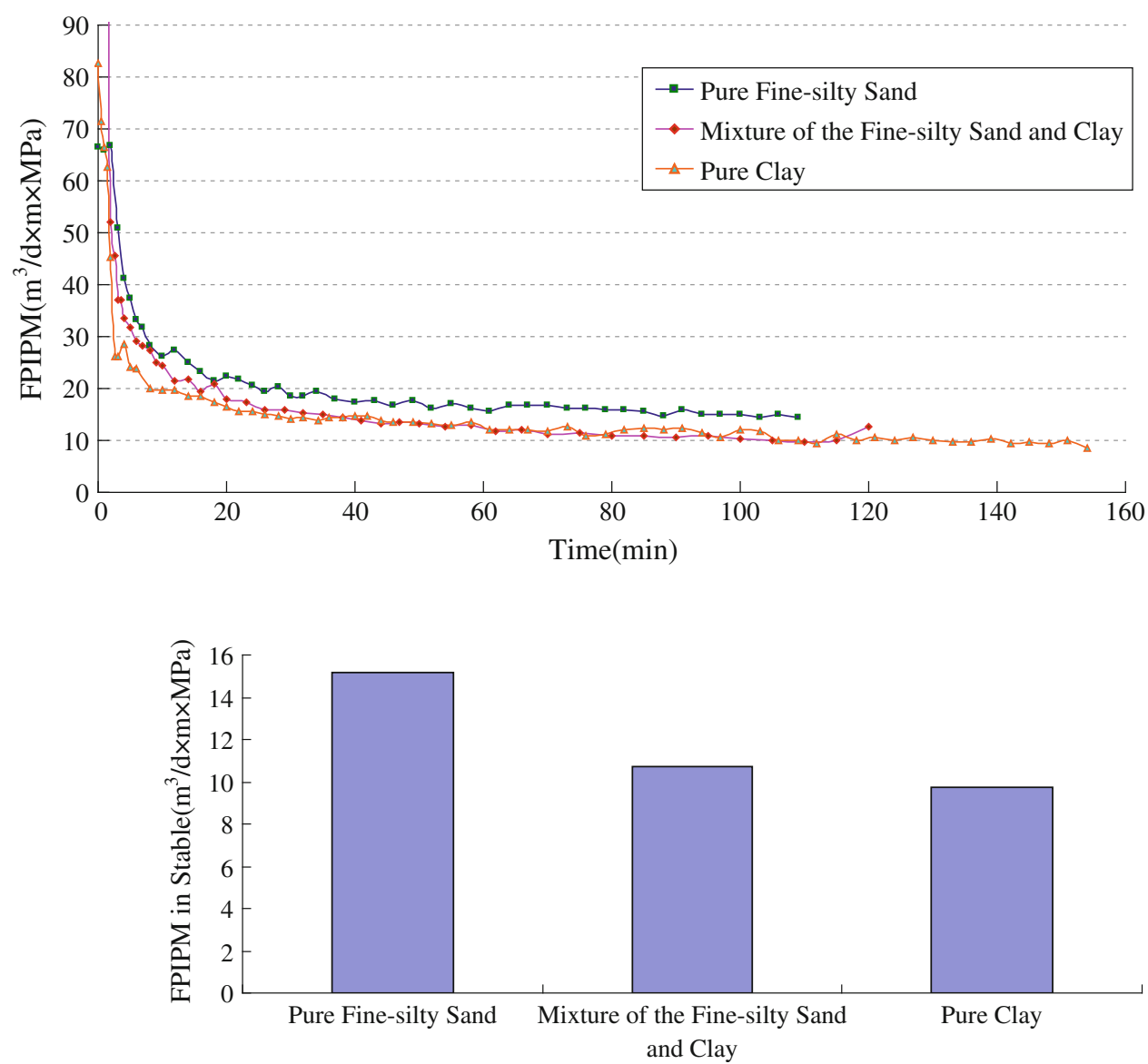

Fig. 10 FPIPM comparative diagram of the pre-packed screen and gravel packing sand control

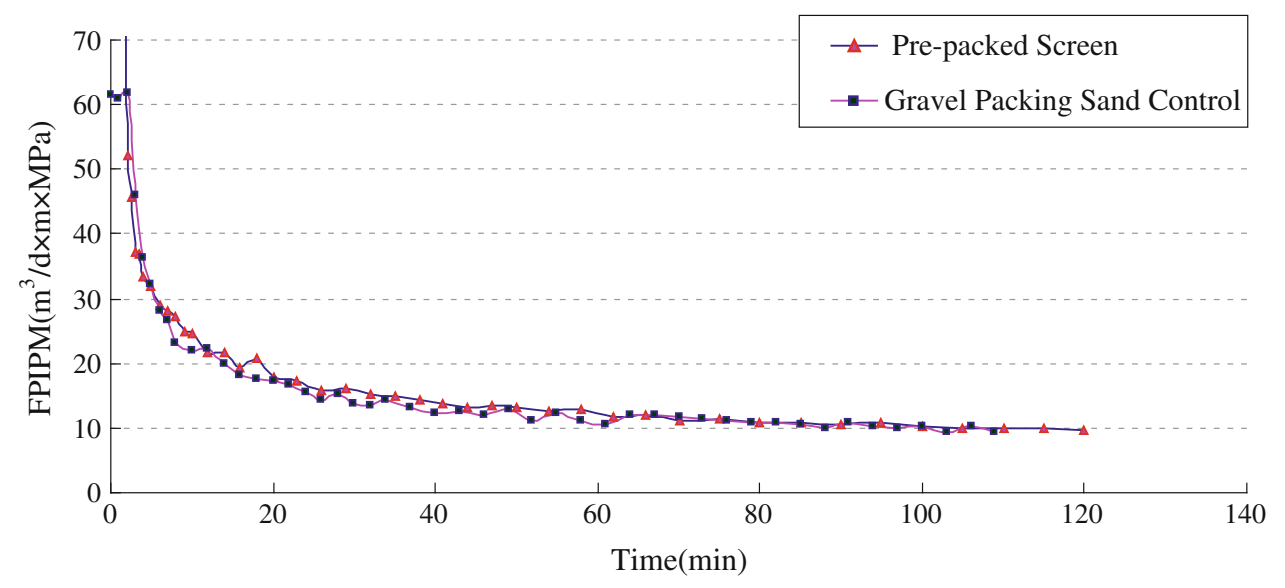

production. Especially the smaller the fine particles diameter is, the more obvious effect the screen blockage is. From the comparison of the different fine particles composition, the jam rate for the pure clay is five times with pure fine-silty sand, and four times with mixture of the fine-silty sand and the clay. When the experiment achieve octet stability, the FPIPM of the pure clay is pretty much equivalent with the mixture of the fine-silty sand and the clay, it declines $30 \%$ with the pure fine-silty sand.

2. From the experiment, it is similar between the mixture of the fine-silty sand and clay experiment result with adding the clay in first and the fine-silty sand in second. It shows that the produce order of different fine particles seem to make any difference to jam the pre-packed screen. But the mud cake has some 
different, it will be discovered that the mud cake has obvious separated layer, when the sanding has a certain order.

3. Whether in deep-water oilfields or offshore oilfields, in the choice of the sand control design former engineers had used gravel packing to make well completion when the content of fine particles is over $5 \%$. This range is relatively conservative. Through several experiments, a new study has shown that pre-packed screen can accomplish the sand control effectively when the content of fine particles reaches $100 \%$. Compared with pre-packed screen and the gravel packing, the FPIPM is all the same. Whether from operation or economically, the formation with high fine particles, the pre-packed screen is more suitable for widely used.

Acknowledgments This paper was supported by the Program for National Science and Technology Major Project of the Ministry of Science and Technology of China (2011ZX05024-003-02).

Open Access This article is distributed under the terms of the Creative Commons Attribution License which permits any use, distribution, and reproduction in any medium, provided the original author(s) and the source are credited.

\section{References}

Bennett C et al (1998) Sand control screen erosion industry joint project, SwRI Project Report 04-8560

Ballard T, Byrne M, Slayter A (2008) Particle size distribution-the challenges and potential solutions. In: 3rd European SPE Sand Management Forum, Panel Session
Byrne M, Waggoner S (2009) Fines migration in a high temperature gas reservoir-laboratory simulation and implications for completion design, SPE 121897-MS

Byrne M, Jimenez MA, Chavez JA (2009) Predicting well inflow using computational fluid dynamics - closer to the truth? SPE 122351-MS

Byrne M, Slayter AG, McCurdy P (2010) Improved selection criteria for sand control-when are "Fines" fines? SPE128038

Farrow C, Munro D, McCarthy T (2004) Screening methodology for downhole sand control selection, paper SPE 88493

Leo E, Hill Jr, Ratterman G, Lorenz M, Fonseca S, Moreira O, Machado F (2002) The integration of intelligent well systems into sand control completions for selective reservoir flow control in Brazil's deepwater and Ronaldo Izetti (Petrobras) SPE78271

Markestad P, Christie O (1996) Selection of screen slot width to prevent plugging and sand production, SPE 31087

McCarthy TA, Mickelburgh IJ (2010) The evolution of sand control completion practices for the enfield deep water development, SPE 127394

Mohamad WA, Maharon J, Mahmoud AW (2008) Temana field pilot implementation: a shift in sand control philosophy to improve well performance, paper SPE 12390

Schwartz D (1969) Successful sand control design for high rate oil and water wells. SPE 2330-PA

Slayter AG, Byrne M, McPhee CA, McCurdy P (2008) Sand management: what are we sure of? Paper SPE 114781

Tiffin CL, King GE, Larese RE et al (1998) New criteria for gravel and screen selection for sand control, paper SPE 39437

Tiffin D, Stein MH, Wang X (2003) Drawdown guidelines for sand control completions, paper SPE 84495

Wan RF (2000) Advanced well completion engineering (third edition) Petroleum Industry Press, Beijing 7:246-288

Wang LH, Deng JG, Zou JL, He BS, Zeng XL (2011) Experimental study on premium screen mesh opening design for reasonable sand control. Chin Offshore Oil Gas 23(2):107-110

Zou HL, Wang XG, Deng JG (2009) Large scale sand production experiments and optimization of sand control for unconsolidated sandstone reservoir. J Liaoning Tech Univ (Nat Sci) 28:142-145 